\title{
SEVERE MUSCULAR RIGIDITY AT BIRTH: MALIGNANT HYPERTHERMIA SYNDROME?
}

\author{
K. Sewall, R. M.M. Flowerdew and P. Bromberger
}

\begin{abstract}
A case of severc muscular rigidity in a premature male infant born by Caesarean Section under general anaesthesia is described. A probable diagnosis of malignant hyperthermia was supported by the clinical symptoms of muscular rigidity and cyanosis, a creatinine phosphokinase of 24,630 l.U. (Normal $0-100$ ) and a urinary myoglobin of $248 \mathrm{mg} / \mathrm{l}$ (normal 6-35). The muscle tone and laboratory values slowly returned to normal over a period of days. Anaesthetic management for a ventriculoperitoneal shunt performed at seven weeks of age included pre and postoperative treatment with dantrolene. No crisis occurred at this time. The parents, who have normal CPK and a negative family history, were advised to treat the child as if he had malignant hyperthermia until such time as a definitive diagnosis can be made.
\end{abstract}

SEVERE MUSClE RIGIDITY at birth is an uncommon event and may have several different aetiologies including, possibly, malignant hyperthermia. The crisis of this syndrome rarely occurs in the very young age groups but has been reported by Henschel and Koh' in a fourteenmonth-old child while dePinna ${ }^{2}$ described a possible aborted crisis in a nine-week old infant. This report describes an infant who was rigid at birth following general anaesthesia for a Caesarean section. The clinical course appeared consistent with a malignant hyperthermia crisis but a muscle biopsy for a positive diagnosis was unobtainable at the time because of the infant's small size.

Subsequently at seven weeks of age the infant required a ventriculoperitoneal shunt. The anaesthetic management for this procedure is described.

\section{CASE REPORT}

A twenty-six-year-old white woman, G5, P1, Ab2, in early labor at an estimated 34 week gestation, was referred to Maine Medical Center with a diagnosis of pregnancy-induced hypertension. Since pelvic ultrasonography indicated a 29 -week foetus, terbutaline was used to inhibit labour and betamethasone to accelerate foetal pulmonary maturation. The hypertension responded to bed rest. On the third day, bifrontal headache, epigastric pain, oedema and a blood pressure of $175 / 105 \mathrm{~mm} \mathrm{Hg}$ indicated progression of the disease. A $4 \mathrm{~g}$ bolus of magnesium sulphate was

K. Sewall, M.D., R.M.M. Flowerdew, M.B.B.S., FFARCS, Associate Anaesthesiologists; P. Bromberger, M.D., Attending Paediatrician, Associate Neonatologist, Maine Medical Center, Portland, Maine 04102, U.S.A.

Canad. Anaesth. Soc. J., vol. 27, no. 3, May 1980 given intravenously followed by a continuous infusion at $2 \mathrm{~g}$ /hour. Four hours later, foetal bradycardia was noted on an external foetal monitor (Doppler). Artificial rupture of membranes produced dark, blood-tinged amniotic fluid and severe foetal bradycardia. Placental abruption was diagnosed; an immediate Caesarean Section was done. Rapid induction with thiopentone, succinylcholine, orotracheal intubation was followed by oxygen, nitrous oxide and 0.5 per cent halothane. Delivery was completed in less than five minutes. Management was uncomplicated. The placenta showed a $\mathbf{4 0}$ per cent separation.

The infant was a $1550 \mathrm{~g}$ male of 32 weeks gestational age. ${ }^{3}$ He had marked muscular rigidity and cyanosis which persisted despite orotracheal intubation and controlled ventilation with oxygen. Chest expansion was poor, although breath sounds were equal. Limb muscles felt as if they were in continuous spasm. The extremities were flexed and could not be straightened.

On arrival at the Neonatal Intensive Care Unit approximately 15 minutes later, the neonate's extremities were still rigid and flexed. The initial arterial blood gas determination indicated combined metabolic and respiratory acidosis, $\mathrm{cH}^{+}$ $83.18 \mathrm{nmol} / \mathrm{l}(\mathrm{pH} 7.08), \mathrm{Pa}_{\mathrm{CO}_{2}} 6.18 \mathrm{kPa}$ ( 51 torr), $\mathrm{HCO}_{3} 16 \mathrm{mmol} / 1, \mathrm{~Pa}_{\mathrm{O}_{2}} 8.0 \mathrm{kPa}$ (60 torr), at $\mathrm{FI}_{\mathrm{O}_{2}}$ 1.0. Temperature was $35^{\circ} \mathrm{C}$, pulse 150 , blood pressure $40 \mathrm{~mm} \mathrm{Hg}$, creatine phosphokinase (CPK) 24,360 I.U. $(0-100)$, ${ }^{*}$ calcium $8.6 \mathrm{mg}$ per cent $(8.5-10.0),{ }^{*}$ magnesium $3.9 \mathrm{mg}$ per cent $(0.8-2.6),{ }^{*}$ and glucose less than $10 \mathrm{mg}$ per cent (35-160).* Urine was "Hemastick" positive but contained no red blood cells on microscopic examination. Muscle rigidity resolved over a four-hour period although muscle firmness per279 
sisted for several days. Ventilatory support was necessary for the first two days but was easily withdrawn. At 48 hours the CPK was 9075 I.U. and urinary myoglobin was $248 \mathrm{mg} / 1(6-35)$.* Thrombocytopenia (platelets $36,000 \mathrm{cu} \mathrm{mm}$ ) and transient renal insufficiency with oliguria, blood urea nitrogen $39 \mathrm{mg}$ per cent $(10-20)^{*}$ and creatinine $1.9 \mathrm{mg}$ per cent $(0.5-1.0)^{*}$ complicated recovery. Cultures from nose, rectum, umbilical cord, blood, cerebrospinal fluid and urine taken prior to antibiotic treatment showed no growth. On the fifth day a lumbar puncture revealed grossly bloody cerebrospinal fuid. On the ninth day a computerized tomography scan confirmed a grade $111^{15}$ intraventricular haemorrhage.

The mother's postoperative course was complicated by anaemia and thrombocytopenia. The pregnancy-induced hypertension subsided slowly. She was discharged on the ninth postoperative day still complaining of decreased visual acuity and requiring diuretic therapy. Careful review of the family history revealed nothing to suggest malignant hyperthermia. Both parents had normal resting CPK.

\section{Anaesthetic Management}

The infant's hydrocephalus, resulting from the intraventricular haemorrhage, was treated initially with serial lumbar punctures. In the seventh week a ventriculoperitoneal shunt was inserted operatively. Anaesthetic management followed the guidelines set forth by Britt, Kwong. Endrenyi.' The infant weighed $2.5 \mathrm{~kg}$. Pretreatment with dantrolene sodium, as suggested by Kerr, Wingard, and Gatz, ${ }^{2}$ and Harrison ${ }^{4}$ was started three days before operation with $3 \mathrm{mg}$ by mouth four times daily, reduced after 24 hours to $3 \mathrm{mg}$ three times daily because the infant became excessively lethargic and fed poorly. Special anaesthetic precautions included a vapour-free anaesthesia machine and circuit (Jackson Rees modification of Ayres-T-piece) and an operating room which had not been used for the previous 24 hours. In addition to the conventional drugs, a supply of intravenous dantrolene,' the drug of choice for treating the crisis of malignant hyperthermia ${ }^{1.5 .6}$ was available in the operating room.

The patient, unpremedicated and with an intravenous line, was taken to the operating room where an electrocardiogram, precordial stetho-

*(_) indicates normal range.

†Eaton Laboratories, Norwich, New York. scope and rectal, nasal, and axillary temperature probes were attached. The room was kept warm $\left(26^{\circ} \mathrm{C}\right)$ to maintain normothermia and a heating/cooling blanket was placed on the operating table. An arterial line was inserted by cut-down using procaine $\mathrm{HCl}$ for local anaesthesia. Body temperature remained normal despite the infant's crying. Anaesthesia was induced with thiopentone and fentanyl and maintained with oxygen, nitrous oxide, and incremental doses of fentanyl. Tracheal intubation was accomplished without relaxants. Respiration was controlled. Ventila. tory compliance appeared decreased but limb musculature remained relaxed. Anaesthesia was uneventful except for a moderate degree of hyperventilation which was shown by arterial blood gas measurements during operation. No acidosis, rigidity or rise in temperature occurred. Residual narcotic depression was antagonized by naloxone.

Monitoring was continued in the Neonatal Intensive Care Unit; recovery was uneventful. The CPK preoperatively was 40 I.U., during operation 851 .U. and 111 I.U., and postoperatively 141 1.U. Postoperative oral dantrolene was continued for three days, during which time the infant remained lethargic and fed slowly, returning to his preoperative state when the dantrolene was stopped. The infant was discharged home on the 63rd day. The parents were warned to treat the child as if he had malignant hyperthermia until a muscle biopsy suitable for in vitro testing might be obtained for definitive diagnosis. At 6 months follow-up, the infant has visual and auditory deficits and his major motor development is delayed.

\section{Discussion}

The striking clinical feature in this case was the muscle rigidity present at birth, associated with a marked elevation of the CPK, and myoglobinuria, all of which gradually resolved over the first week of life. The differential diagnosis of transient muscle rigidity in the newborn includes neonatal tetanus, tetany, encephalitis, meningitis, kernicterus, heroin withdrawal, and phenothiazine intoxicalion, ${ }^{7}$ all of which were unlikely in this case. Reported causes of persistent muscle rigidity at birth include continuous peripheral nerve hyperactivity, ${ }^{7}$ degenerative or destructive cervical cord lesions, ${ }^{8}$ and congenital myopathies. ${ }^{y}$ Sclerema neonatorum, a woody induration of subcutaneous tissue which occurs in 
severely ill premature and term infants, is often associated with overwhelming sepsis or a severe hypotensive episode and becomes apparent 24 to 48 hour's after the precipitating event. This case is unique in that muscle enzymes, muscle mass and tone all returned to normal within a week of birth.

Severe neonatal asphyxia is most often associated with hypotonia at birth. " Maternal general anaesthesia ${ }^{12}$ and neonatal hypermagnesaemia ${ }^{13}$ are other factors which predispose to flaccidity at birth. This infant was exposed to all of these factors but was nevertheless rigid at birth. Myolysis with elevation of CPK, myoglobinuria, and transient renal insufficiency have been reported in a term asphyxiated and septic infant, but that infant had no abnormalities of muscle tone and myolysis was attributed to the hypoxic insult. ${ }^{14}$

This infant displayed the following clinical features of malignant hyperthermia (MHS): metabolic acidosis. muscular rigidity, elevated CPK, and myoglobinuria. Elevated temperature was absent, but a small premature infant with large surface area to volume ratio and limited mechanisms for thermogenesis rapidly loses heat to a cooler environment.

Wingard' has postulated that malignant hyperthermia represents an acute stress syndrome of man because these patients are susceptible to sudden death from a variety of stimuli. Great emphasis has been placed on the role of anaesthetic drugs as trigger agents but other emotional and physical stimuli may be equally important. In the family investigated by him at least half the malignant hyperthermic reactions occurred outside the operating room. Placental abruption would impede the passage of the anaesthetic agents, but would also contribute to foetal hypoxia which was manifested by foetal bradycardia. It is likely that the trigger factors were a combination of physical and pharmacological agents in this case.

The diagnosis of MHS is normally confirmed by muscle biopsy, but the infant's small size precluded an adequate sample. Other features that would help confirm the diagnosis include a positive family history and the fractionation of creatinine phospho-kinase into its isoenzymes. The absence of a positive family history of MHS is by no means unique to this case. Paper chromatography of the CPK isoenzymes has been described by Wingard' who noted that the newborn has both the MM and the BB isoenzyme whereas the adult has only the MM isoenzyme. In patients with crisis, however, all three enzymes, MM, BB and MB are present. Unfortunately enzyme fractionation, which might have helped confirm the diagnosis, was not done.

Even though the diagnosis of MHS was equivocal the clinical features were sufficient to warrant MHS precautions for anaesthetic and surgical procedures until a definite answer is obtained.

An intraventricular haemorrhage occurred, probably as a result of perinatal asphyxia and prematurity. Post-haemorrhagic hydrocephalus required the operative placement of a ventriculoperitoneal shunt at seven weeks of age. To our knowledge there are no reports of the elective anaesthetic management of an infant of this size with suspected malignant hyperthermia. The protocol described by Britt, et al.' was modified to omit premedication and to reduce the number of intraoperative blood samples because of the infant's small size. Pretreatment with dantrolene initially caused lethargy and poor feeding, but the infant improved with a reduced dose. Anaesthesia and the postoperative period proceeded smoothly. The decreased ventilatory compliance noted during the operation may have been secondary to the fentanyl or may have been the result of assisted ventilation in the newborn period.

Exposure to anaesthesia or stress does not invariably produce a crisis in patients susceptible to MHS. We cannot be sure that our pre-anaesthetic and anaesthetic management prevented a crisis in the patient, but the infant did not appear to suffer any ill effects from the procedures used.

\section{ACKNOWLEDGEMENTS}

We are grateful to Linda Gauvin and Ethel Cleaves for their typing skills and to Dr. C.W. White for reviewing the manuscript.

\section{REFERENCES}

1. Henschel, E.O. Malignant hyperthermia. Current Concepts. New York. Appleton-Century-Crofts (1977).

2. Aldrete. J., \& BritT. B.A. Second International Symposium on Malignant Hyperthermia. New York. Grune \& Stratton (1978).

3. Ballard, J.L.. Kazmaler, K. \& Driver, M. A simplified assessment of gestational age. Pediatric Research $/ 1: 374$ (1977).

4. Harrison, G.G. The prophylaxis of malignant hyperthermia syndrome by dantrolene sodium in swine. British Journal of Anaesthesia 49: 315 (1977). 
5. Harrison, G.G. Control of malignant hyperthermia syndrome by dantrolene sodium. British Journal of Anaesthesia 47: 62 (1975).

6. Gronert, S.A., Milde, J.M. \& Tmeye, R.A. Dantrolene in procine malignant hyperthermia. Anesthesiology 44: 488 (1976).

7. Black, J.J., Garcia-Mullin, R., Good, E. \& BRown, S. Muscle rigidity in a newborn due to continuous peripheral nerve activity. Archives Neurology 27: 413 (1972).

8. Penry, J.k., hoefnagel, D., Van Den Moort, S. \& Denny-Brown, D. Muscle spasm and abnormal postures resulting from damage to anterior neurones in the spinal cord. Archives Neurology 5 : $500(1960)$.

9. Ringle, S.P., Neville, H.E., Duster, M.C. \& CARroll, J.E. A new congenital neuromuscular disease with trilamminar muscle fibres. Neurology 28: 282 (1978).

10. Warwick, W.J., Ruttenberg, H.D. \& Quie, P.G. Sclerema Neonatorum-A sign, not a disease.
Journal of the American Medical Association 184 $9.94(1963)$.

11. Menkes, J.H. "Perinatal trauma" in Textbook of Child Neurology. Lea \& Ferbiger. New York (1974).

12. Hollman, A.I., Jouppila, R., Koivisto, M. Maatta, L., Pihlajamiemi, R., Puukka, M., \& RANTAKYLA, P. Neurologic activity of infants following anaesthesia for caesarian section. Anesthesiology 48: 350 (1978).

13. Goodman, L.S., \& Gilman, A. The Pharmocological Basis of Therapeutics. 5th Ed. New York. The MacMillan Co. (1975).

14. Haftel, A.J., Eichner, J., Haling, J. \& WILson, M.L. Myoglobinuric renal failure in a new born infant. J. Pediatrics 93: 1015 (1978).

15. Papile, L.A., Burstein, J., Burstein, R. \& KOFFLER, $H$. Incidence and evolution of subependymal and intraventricular hemorrhage: A study of infants with birth weights less than 1500 gms. J. Pediatrics 92: 529(1978).

\section{RÉSUMÉ}

Un cas de rigidité musculaire sévère chez un prématuré de sexe masculin né sous anesthésie générale et par césarienne est présenté. Le diagnostic probable d'hyperthermie maligne a été documenté par les symptômes cliniques de rigidité musculaire et de cyanose, une créatinephosphokinase à 24.630 U.I. $(\mathrm{N}=0-100)$ ct une myoglobinurie à $248 \mathrm{mg} / \mathrm{l}(\mathrm{N}=6-35)$. Le tonus musculaire ct les valeurs de laboratoire sont revenus à la normale après quelques jours. La conduite anesthésique pour un shunt ventriculo-péritonéal réalisé à la septième semaine de vie a consisté en une préparation pré et post-opératoire au dantrolène et s'est déroulé sans crise d'hyperthermie. Les parents qui ont des CPK normales et une histoire familiale négative, ont été avertis de considérer l'enfant comme porteur d'hyperthermie maligne jusqu'à ce qu'un diagnostic définitif soit atteint. 